\title{
PERANCANGAN CD KATALOG UNTUK PENYAMPAIAN LAYANAN INFORMASI BERBASIS MULTIMEDIA PADA RUMAH SAKIT PERSAHABATAN
}

\author{
Nilo Legowo; Agustinna Yosanny; Bagus Prabowo \\ Jurusan Teknik Informatika, Fakultas Ilmu Komputer, Bina Nusantara University \\ Jln. K.H. Syahdan No 9, Palmerah, Jakarta Barat 11480 \\ nlegowo@binus.edu
}

\begin{abstract}
$C D$ katalog developed is an effort to improve service quality and effectiveness of delivering information to visitors Persahabatan Hospital. The method used is the method of literature, methods of analysis and design methods. Methods Literatur include the study of literature references relating to problems and applications. Methods include analysis of field studies with a survey on the current system as well as an analysis of surveys, interviews, and questionnaire distribution. The design method includes designing the menu structure, State Transition diagrams, screen design, database use, and module specifications. The results obtained in the form of multimedia CD-based catalog that presents the completeness of the information, such as facilities Persahabatan Hospital, clinic, the site plan, and schedule a doctor. The conclusion was based on a multimedia CD Catalog can be a new alternative as a medium to facilitate the search for location information and profile hospital. With the CD catalog is expected to visitors and prospective participants can find information about the Friendship Hospital, more easily, and help the Friendship Hospital in providing information to visitors Hospitals.
\end{abstract}

Keywords: analysis and design, CD catalogue, multimedia, hospital service

\begin{abstract}
ABSTRAK
CD katalog dikembangkan dalam upaya meningkatkan kualitas pelayanan dan efektifitas penyampaian informasi kepada pengunjung Rumah Sakit Persahabatan,. Metode penelitian yang digunakan adalah metode pustaka, metode analisis dan metode perancangan. Metode pustaka meliputi studi literatur yang berhubungan dengan masalah dan aplikasi. Metode analisis meliputi studi lapangan dengan survei pada sistem yang sedang berjalan serta analisis terhadap survei, wawancara, dan penyebaran kuesioner. Metode perancangan meliputi perancangan struktur menu, State Transition Diagram, perancangan layar, database yang digunakan serta spesifikasi modul. Hasil yang dicapai berupa CD Katalog berbasis multimedia yang menghadirkan kelengkapan informasi seperti fasilitas Rumah Sakit Persahabatan, poliklinik, denah lokasi, dan jadwal dokter. Kesimpulannya adalah CD Katalog berbasiskan multimedia dapat menjadi alternatif baru sebagai media untuk memudahkan pencarian informasi lokasi dan profil rumah sakit. Dengan adanya CD Katalog ini diharapkan pengunjung dan calon peserta dapat mencari informasi seputar Rumah Sakit Persahabatan, dengan lebih mudah, dan membantu pihak Rumah Sakit Persahabatan dalam memberikan informasi kepada pengunjung Rumah sakit.
\end{abstract}

Kata kunci: analisis dan perancangan, CD katalog, multimedia, pelayanan rumah sakit 


\section{PENDAHULUAN}

Dalam kegiatan operasional suatu Rumah Sakit Persahabatan, penyampaian informasi seperti halnya jadwal praktek dokter, fasilitas yang tersedia, berita kegiatan, dan lokasi yang akan dituju pengunjung, penyampaiannya harus diupayakan dengan baik dan benar, sehingga pengunjung akan merasa nyaman atas pelayanan yang dihadirkan. Namun di saat yang bersamaan, terkadang menjadi kesulitan bagi pengunjung sendiri untuk mencari dan menemukan informasi secara cepat. Kendala seperti diatas juga dirasakan oleh pihak Rumah Sakit Persahabatan Hal ini dikarenakan informasi tentang Rumah Sakit, yang begitu banyak, tetapi tidak tercakup dalam satu media yang ringkas, cepat dan tepat sasaran.

Dengan melihat permasalahan di atas, maka Rumah Sakit, membutuhkan suatu media informasi baru. Untuk mempermudah pengunjung dalam memperoleh informasi seputar Rumah Sakit dibuatlah sebuah CD Katalog yang dapat memberikan informasi tentang seluk beluk Rumah Sakit secara jelas, padat, dan mudah digunakan. Yang dimaksud CD Katalog disini adalah sebuah media interaktif yang disusun dari berbagai komponen multimedia yang disuguhkan melalui komputer guna menyampaikan berbagai informasi kepada pengguna.

Batasan ruang lingkup dari aplikasi yang diinginkan oleh Rumah Sakit Persahabatan, adalah rancangan CD katalog yang akan dibuat berhubungan dengan informasi yang dibutuhkan pengunjung rumah sakit, dalam aplikasi CD katalog ini akan menyajikan informasi tentang profil rumah sakit fasilitas yang disediakan, jadwal praktek dokter, tips kesehatan, pelayanan unggulan, berita dan kegiatan yang diadakan.

Tujuan dari penulisan penelitian ini adalah merancang suatu sistem CD katalog berbasiskan multimedia untuk rumah sakit, serta memberikan kemudahan bagi pengunjung rumah sakit dalam memperoleh informasi. Manfaat bagi Rumah Sakit Persahabatan adalah : Meningkatkan kualitas pelayanan informasi profil rumah sakit secara umum, Meningkatkan efisiensi dan efektifitas penyampaian informasi pihak Rumah Sakit kepada pengunjung. Sedangkan manfaat bagi pengunjung rumah sakit, adalah memudahkan pengunjung dalam memperoleh informasi tentang rumah sakit. Mempermudah pengunjung dalam menemukan lokasi yang dituju khususnya untuk lokasi poliklinik, yaitu melalui denah lokasi yang dihadirkan pada sistem CD Katalog ini.

\section{METODE}

Menurut Pressman (2001), rekayasa piranti lunak adalah penerapan dan pemakaian prinsip rekayasa dalam rangka mendapatkan piranti lunak ekonomis yang terpercaya dan bekerja secara efisien pada mesin komputer. Rekayasa piranti lunak mencakup tiga elemen yang mampu mengontrol proses perkembangan piranti lunak, yaitu metode, alat-alat bantu, dan prosedur-prosedur.

Metode merupakan cara-cara teknis membangun piranti lunak yang terdiri dari perancangan proyek dan estimasi, analisis kebutuhan sistem dan piranti lunak, perancangan struktur data, arsitektur program, prosedur algoritma, pengkodean, pengujian dan pemrograman. Alat-alat bantu menyediakan dukungan otomatis atau semi otomatis untuk metode-metode seperti Computer Aided Software Engineering (CASE) yang mengkombinasikan piranti lunak dan piranti keras dan software engineering database (tempat penyimpanan yang mengandung informasi yang penting tentang analisis, perancangan, pembuatan program, dan pengujian) 
untuk pengembangan piranti lunak yang sejalan dengan Computer Aided Design/Engineering (CAD/E) untuk piranti keras. Prosedur-prosedur untuk menghubungkan alat-alat bantu dengan metode. Tujuan dari prosedur yaitu untuk mendapatkan piranti lunak yang efisien, berguna dan ekonomis.

Metode dalam mengembangkan program ada urutan atau siklus yang merupakan tahapan-tahapan pengembangan software aplikasi. Dengan model proses yang dipilih adalah model Waterfall, diharapkan proses pengembangan program akan berjalan dengan baik. Tahapan pengembangan program dapat kita bagi menjadi tahapan-tahapan, yaitu analisis, rancangan, pengembangan, testing dan implementasi, dan maintenance.

Analisis, merupakan tahapan paling awal dalam siklus pengembangan program pada tahapan ini lebih banyak difokuskan kepada ide awal atau sketsa mengenai program yang akan dikembangankan secara keseluruhan. Dari hal-hal yang sifatnya konseptual sampai kearah fasilitas dan ruang lingkup program itu nantinya. Tahap ini nantinya akan dijadikan pikiran utama yang akan dikembangkan lebih jauh pada tahap-tahap selanjutnya.

Rancangan, bukan hanya desain tampilan saja, melainkan juga perancangan keseluruhan program yang ingin dikembangkan. Dari mulai format teks, tata letak, penggunaan warna dan tema serta sampai fasilitas apa saja yang ditampilkan atau disediakan di dalam program. Sementara, pada tahap pengembangan, pembuatan program secara nyata (coding) dilakukan.

Testing dan Implementasi, akan dites apakah sudah sesuai dengan rancangan awal dan tepat maka masuk ke tahap berikutnya yaitu implementasi. Setelah program telah diimplementasikan, maka selanjutnya adalah tahapan maintenance, yaitu perawatan dari program yang ada. Perawatan yang dimaksud adalah dilakukannya pemeliharaan sistem atau fasilitas maupun data dari program yang ada.

Metode penulisan yang digunakan adalah metode pustaka, penulis melakukan studi literatur yang berhubungan dengan masalah dan aplikasi. Metode analisis yang digunakan adalah studi lapangan dengan melakukan survei pada sistem yang sedang berjalan, analisis survei, wawancara langsung pada pihak rumah sakit persahabatan serta menyebarkan kuesioner pada pengunjung rumah sakit persahabatan, dan metode perancangan yang digunakan adalah metode perancangan terstruktur yang terdiri dari perancangan struktur menu, state transition diagram ( std ), perancangan layar, perancangan database dan spesifikasi modul. Gambar 1 merupakan bagan alur metode penelitian

Multimedia berisi empat komponen penting dalam multimedia, yaitu harus ada komputer multimedia yang mengkoordinasikan apa yang harus dilihat dan didengar, harus ada link yang menghubungkan dengan informasi, harus ada alat navigasi yang memantau, menjelajah jaringan informasi yang saling terhubung, multimedia menyediakan tempat untuk mengumpulkan, memproses, dan mengkomunikasikan informasi dari ide sendiri. (Hofstetter, 2001).

\section{HASIL DAN PEMBAHASAN}

Spesifikasi Software yang dibutuhkan untuk penerapan CD Katalog ini adalah Microsoft Windows 2000, Xp atau lebih, Macromedia Flash 8 juga menyediakan fasilitas filter dan komponen-komponen tambahan, Microsoft Visual Basic 6, Adobe Photoshop 7, Microsoft 
Access 2003. Spesifikasi Hardware yang disarankan untuk menjalankan aplikasi ini adalah sebagai berikut : Processor Pentium IV 2,0 GHz atau lebih, Memory $256 \mathrm{MB}$ atau lebih, Harddisk dengan ruang kosong minimum 3 GB, Soundcard dan Speaker, VGA Card sebesar 64 MB atau lebih, Monitor LCD 17” dengan resolusi layar 1024x768 pixel atau lebih.

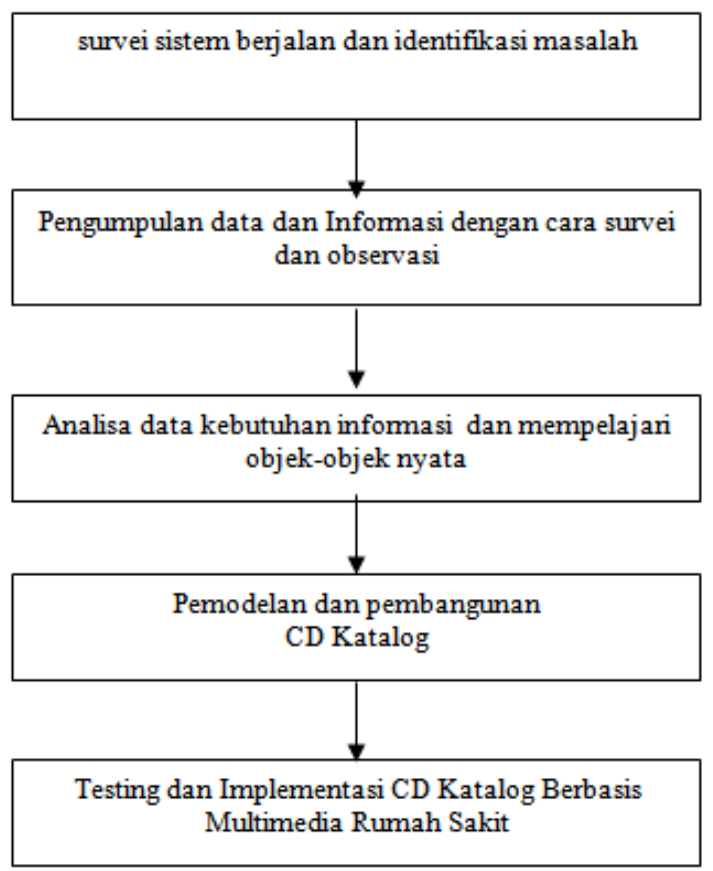

Gambar 1 Bagan alur metode penelitian

Spesifikasi hardware yang telah disebutkan di atas adalah spesifikasi hardware yang bisa menjalankan aplikasi secara baik. Apabila CD Katalog ini dijalankan dengan menggunakan spesifikasi hardware yang lebih rendah dari yang disarankan tersebut, CD Katalog ini tetap dapat dijalankan namun ada beberapa bagian yang tidak dapat ditampilkan dengan baik, misalnya animasinya menjadi terputus ataupun proses pembacaan dari database berlangsung lebih lambat.

Implementasi Sistem Jaringan CD Katalog RS, Sistem ini berjalan melalui jaringan (LAN) dari 2 buah komputer yang saling berhubungan. Komputer pertama berfungsi sebagai Back End yaitu server dan pengontrolan admin, diletakkan di dalam meja kerja customer service dan komputer kedua berfungsi sebagai Front End yaitu komputer yang digunakan oleh user.

Implementasi Penempatan dan Rancangan CD Katalog RS, Untuk saat ini monitor CD Katalog akan ditempatkan di samping meja customer service yang berada di lobby utama lantai 1, oleh karena itu pengunjung dapat menggunakan langsung CD Katalog ini ketika mereka mengunjungi RS,. Bahan-bahan yang akan digunakan pada CD Katalog ini terbuat dari Fiber, dengan layar flat TFT (Thin Film Transistor) dan didesain sedemikian rupa agar mudah dan nyaman pada saat digunakan oleh user. Rancangan monitor untuk CD Katalog ini dapat dilihat seperti gambar di bawah ini. 
Tampilan Layar Front End Pada CD Katalog RS pertama kali dijalankan, ditampilkan Layar Pembuka yang berupa Visi Misi dari RS , beserta menu lainnya. Menu-menu tersebut adalah Layanan Unggulan, Poliklinik, Fasilitas, Berita \& Kegiatan, Video profil Rumah Sakit Persahabatan. Tampilan layar untuk CD Katalog ini dapat dilihat seperti Gambar 2.

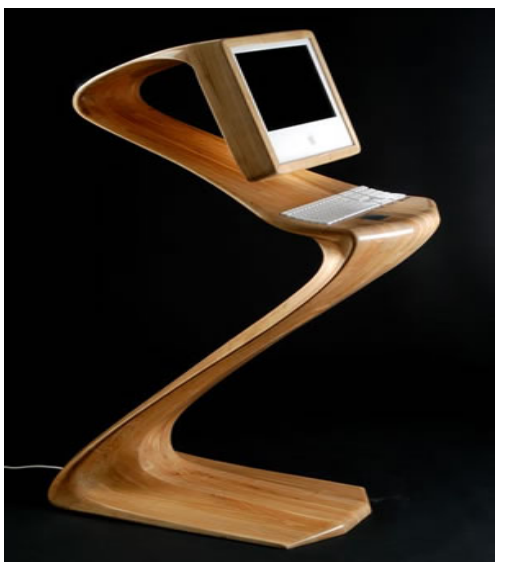

Gambar 2 Rancangan CD Katalog Rumah Sakit

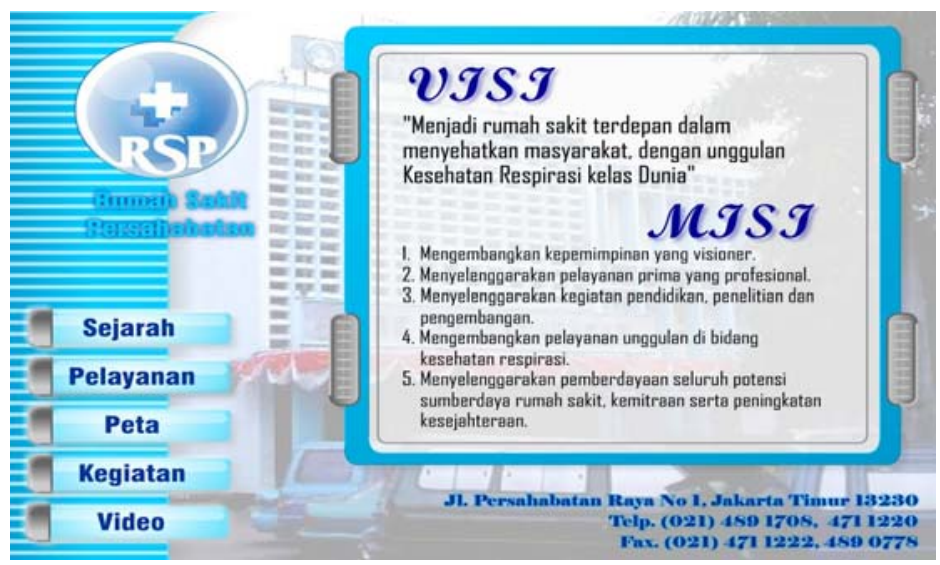

Gambar 3 Tampilan Layar Menu Utama

Tampilan Layar back end (admin) pada CD katalog RS ,Layar Login untuk admin dibuat agar hanya User Admin saja yang berhak mengakses layar pemeliharaan. Syaratnya User Admin harus memasukkan username dan password sesuai validasi dari database login. Dengan layar pemeliharaan, User Admin dapat merubah, menambah atau menghapus data pada kategori yang dipilih. Berikut ini tampilan layar Admin - Login:

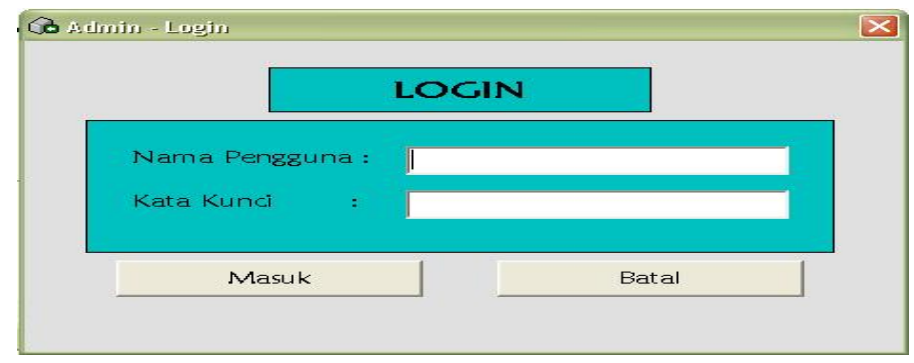

Gambar 4 Tampilan Layar Admin - Login

Berdasarkan hasil kuesioner yang telah diperoleh, penulis menarik kesimpulan bahwa pengunjung RSUP memerlukan informasi jadwal praktek dokter, Informasi yang didapatkan pengunjung selama ini kurang jelas dan kurang lengkap. Hal ini dapat disebabkan gambaran yang diberikan petugas kepada pengunjung kurang jelas, di mana masingmasing petugas atau staf memiliki pengetahuan yang berbeda tentang RSUP , sehingga tidak semua staf dapat memberikan informasi yang lengkap dan jelas. Kesulitan yang dialami oleh pengunjung RSUP, dalam mencari informasi adalah membutuhkan waktu yang lama, Keberadaan informasi RSUP , tidak banyak diketahui pengunjung.

Hasil rancangan aplikasi yang telah dibuat perlu dilakukan pembahasan dengan melakukan pengetesan apakan tampilan dan kinerja aplikasi CD katalog yang dibuat sudah memenuhi ketentuan 8 aturan emas dalam Interaksi Manusia dan Komputer. Sistem yang baik hendaklah user-friendly. Suatu sistem yang user-friendly menurut Shneiderman, harus memenuhi lima kriteria antara lain waktu untuk belajar yang tidak lama, kecepatan penyajian 
informasi sehingga informasi yang tersedia adalah yang paling akurat, tingkat kesalahan pengguna yang rendah, mudah dihafal sesuai dengan jangka waktu yang pendek, dan kepuasan pemakai.

Program CD katalog ini memiliki kelebihan dalam kelengkapan informasi yang disajikan dan kemudahan pemakaian, contohnya (1) kelengkapan informasi yang diberikan khususnya informasi yang paling sering dicari pengunjung seperti jadwal dokter, pelayanan / fasilitas yang disediakan, denah lokasi, dan informasi lainnya; (2) kemudahan perubahan data seperti tips, berita dan kegiatan melalui aplikasi admin sehingga CD Katalog ini akan selalu up to date; (3) penggunaannya yang mudah dapat dilihat dari tidak terlalu banyaknya menu namun informasi yang berada di dalamnya padat dan mencakup seluruh informasi yang selama ini dibutuhkan pengunjung.

Dari hasil pembahasan yang dilakukan bahwa CD Katalog ini juga memiki kekurangan, seperti CD Katalog ini hanya dapat ditampilkan dengan baik dengan resolusi 1024 x 768 pixel, tidak ada fasilitas search yang memungkinkan user dapat mencari informasi yang diinginkan, karena CD Katalog ini menggunakan banyak gambar, suara, video serta animasi dengan fps (frame per second) yang tinggi, sehingga untuk menjalankan aplikasi CD Katalog ini dibutuhkan komputer dengan spesifikasi hardware yang cukup tinggi.

Spesifikasi hardware yang telah disebutkan di atas adalah spesifikasi hardware yang bisa menjalankan aplikasi secara baik. Apabila CD Katalog ini dijalankan dengan menggunakan spesifikasi hardware yang lebih rendah dari yang disarankan tersebut, CD Katalog ini tetap dapat dijalankan namun ada beberapa bagian yang tidak dapat ditampilkan dengan baik, misalnya animasinya menjadi terputus ataupun proses pembacaan dari database berlangsung lebih lambat.

Dari kesimpulan yang ada untuk meningkatkan kinerja CD katalog ini disarankan: CD Katalog menggunakan komputer dengan spesifikasi hardware yang tinggi, dengan resolusi 1024 x 768 pixel. Maintenance CD Katalog ini sebaiknya dipegang oleh seorang administrator yang berkepentingan saja, oleh karena itu username dan password harus diperhatikan dan dirahasiakan.Penempatan CD Katalog ini sebaiknya harus mudah diakses, misal pada tiap lantai, untuk membantu pengunjung mendapatkan informasi, dan menghindari antrian yang mungkin terjadi dalam pengaksesan CD Katalog ini.

\section{PENUTUP}

Dari hasil analisis dan evaluasi terhadap perancangan CD Katalog ini, maka dapat diambil beberapa kesimpulan sebagai berikut : CD Katalog mempermudah pengunjung Rumah Sakit Persahabatan dalam memperoleh informasi seputar Rumah Sakit Persahabatan.,CD Katalog berguna untuk membantu kegiatan operasional Rumah Sakit Persahabatan, dalam hal penyampaian informasi Rumah Sakit Persahabatan yang beragam. CD Katalog mendukung penggunaan media-media penyampaian informasi lain yang ada di Rumah Sakit Persahabatan, seperti papan informasi, brosur, customer service, dan menjadi alternatif bagi pihak Rumah Sakit Persahabatan, untuk menyampaikan informasi kepada pengunjungnya. 


\section{DAFTAR PUSTAKA}

Hofstetter, F. (2001). Multimedia Literacy (3rd ed.). Irwin: McGraw-Hill.

Pressman, R. S. (2001). Software Engineering A Practitioner's Approach (5th ed.). Singapore: McGraw-Hill. 